\title{
Principles of using modern IT trends in maritime shipping
}

\author{
Ilya Shipunov ${ }^{1, *}$, Anatoliy Nyrkov ${ }^{1}$, Vitaly Korotkov ${ }^{1}$, Oleg Alimov ${ }^{1}$, and Tatiana Knysh ${ }^{1}$ \\ ${ }^{1}$ Admiral Makarov State University of Maritime and Inland Shipping, St. Petersburg, Russia 198035
}

\begin{abstract}
The paper discusses modern technologies from the field of the Internet of Things that can be used to organize and manage navigation of ships, including autonomous ones. The use of these technologies will increase the level of safety and cybersecurity on ships.
\end{abstract}

\section{Introduction}

Today, IT trends are increasingly being introduced into the modern shipping industry. In the course of this work several most promising IT trends for the industry will be highlighted. And proposed options for their use in marine transport. It should be noted that the modern development of IT industry is a complex process in which the development of one component entails the development of another one. It depends on a high level of dependence of the components on each other. However, every new step in development brings not only positive effects, it also brings a certain pool of problems related primarily to security, the cost of implementation and training. Moreover, today's level of automation and robotization requires innovative legislative solutions. A lot of legal acts need to be brought to modern reality.[1]

So, let us consider modern IT trends applicable in the nowadays shipping and maritime industry.

\section{Internet of things in maritime transport}

Nowadays nobody will dispute the fact about unimaginably fast introduction of Internet technologies of things into our life. It is so comfortable to take some familiar devices to process and teach them to interact with each other. In addition, it is necessary to teach devices to analyze the environment, to accumulate information and take certain actions in a particular situation. Give such devices a space to exchange information and commands with each other (to a network) and the result will be a great helper to manage the process. [2]

The main task at creation of such devices is "training" of perception of environment or more concrete object of observation. Today's engineers and programmers cope with this task better and better. Such devices are highly likely to be used in increasingly complex processes.

\footnotetext{
* Corresponding author: mr-shis@yandex.ru
} 
The most difficult technical task in maritime transport is a creation of crew-free ships. Almost all major players of the maritime transport market are working in this direction. One of the difficulties in the design of ships of this type is to solve the problem of team replacement. However, the mechanical actions of the crew with modern robotization capabilities are real to imitate, but it is very difficult to replace the human analysis of the environment.[3] Everybody understands that the development of certain managerial decisions often comes from personal experience and its application to the observed picture of what is happening.[4] IoT devices are the most suitable way to solve this problem.

Let's consider a technological layer of such project. Here there is a point of crossing of streams of the information arriving from external sources (like satellites) and sources internal - various onboard systems and sensors. Introduction of devices IoT at the given level will allow to provide not only due level of forecasting, but also to realize the mechanism of accumulation of experience which then can serve for perfection of the mechanism of decision-making. Such technologies can serve as a foundation in navigation systems of crewless ships. The processing of satellite information on the marine environment will make it possible to build the most efficient routes. The ability of devices to exchange messages with devices that have only been detected or with familiar devices that have disappeared from the field of vision will help to teach such systems to see each other at sea and avoid emergencies. Communication of systems with the coastal infrastructure will allow to prepare the port in advance for the arrival of the vessel and will provide the port administration with all necessary information about the vessel and cargo.

Another field of using IoT in maritime transport is the creation of intelligent cargo infrastructure on board the vessel. Such infrastructure should include smart holds, smart containers and control communication center.[5]

Smart containers must monitor and adjust temperature, humidity and air pressure as needed. It should also record the vibrations and position of the container both in general geolocation and its location on the vessel after loading. The interaction center will allow on shore to track all the telemetry from the container, which will help in resolving disputes about cargo damage during the transportation. Knowledge of the location will always allow tracking the entire route of the cargo.[6] The scheme of interaction is shown below.

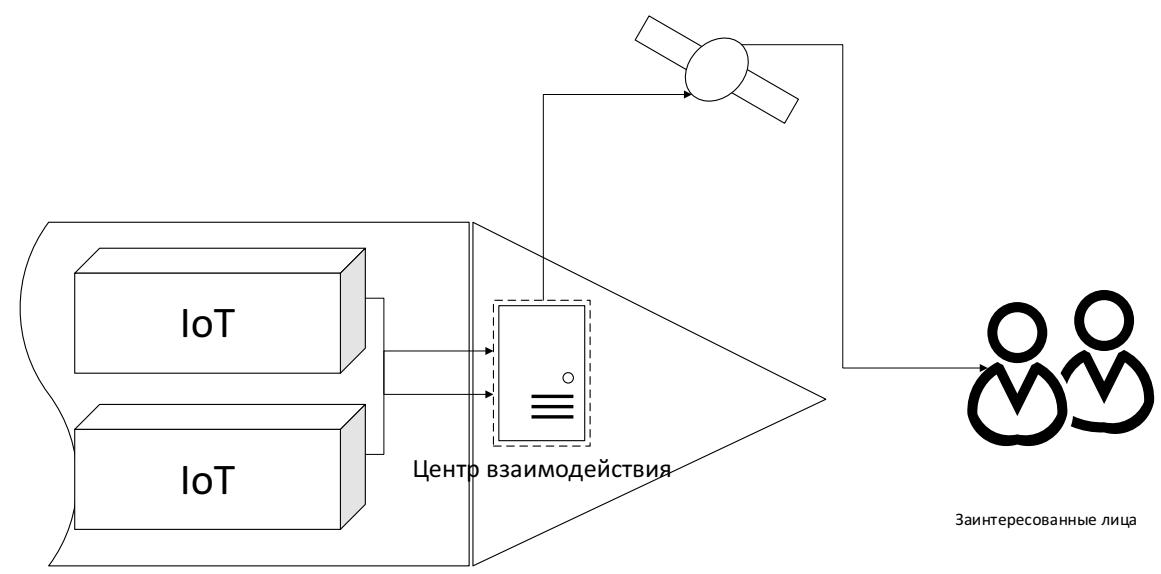

Fig 1. Smart container scheme of interaction.

Such developments are already being implemented by CMA CGM in its work cycle. Traxen technology is used to organize a smart cargo system (Figure 2). This technology is used to track refrigerated containers.[7] For such system, the Bougainville container ship was re-equipped. All containers on board form a single smart network and always communicate with the onshore office of the company. 


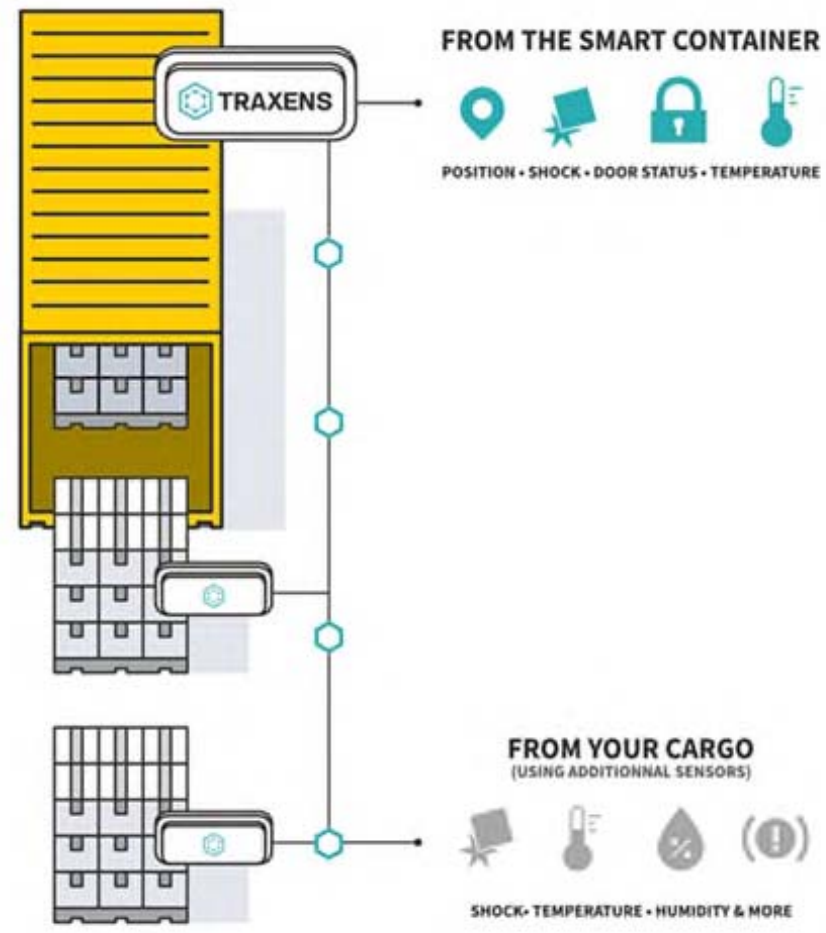

Fig 2. Smart Traxen container.

In the case of crewless ships, a very important aspect is the communication of the sea drone with the shore for its intellectual integration into the sea traffic. The objects of observation and analysis can be time parameters for the manoeuvring of ships when entering the port. Maintaining records and storage of such data will reduce downtime and speed up preparation for vessel reception. Best practices for such implementations can be observed at the port of Rotterdam. This port in association with IBM is working to implement, digitize and process smart devices. At this point, the port can begin preparations while the ship is just over 40 kilometers away. This improves both the efficiency of the port and its security.

With the help of IoT it is also possible to solve a range of tasks related to navigation in difficult conditions. Difficult conditions mean a lot of traffic on the routes, as well as bad weather conditions.

Such intellectual system based on the data from sensors and on processing algorithms should build spatial model of obstacles and dangerous zones. It should influence a course of maneuvering of a ship. It will increase the level of safety of navigation.

The modern level of development and cloud training of artificial intelligence (AI) allows to build the above described intellectual systems using AI.[8] As a basis we can take Google Cloud Machine Learning Engine technology. This system is based on AI and can help to recognize, classify and track objects that a ship may encounter at sea.

A possible functional diagram of such a system is shown in the figure below. 


\section{Sensors}
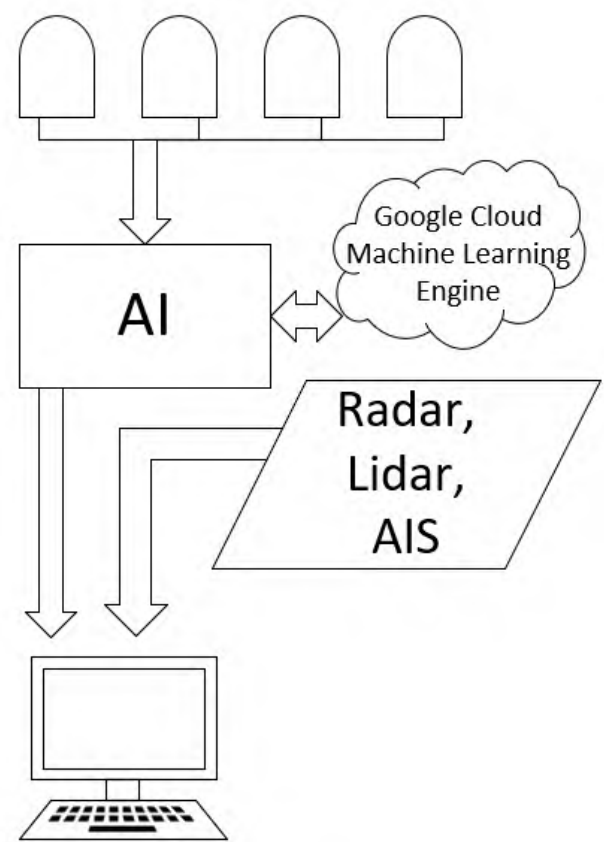

Navigation

system

Fig 3. Possible scheme for building a smart navigation system.

The IoT can also be used to control the ship's departure or to dock the ship independently. The IoT data can be used to secure the vessel in block-chains. This factor will allow developing the field of smart contracts and cargo control by insurance companies. [9]

\section{Using of Blockchain technology in maritime transport}

Blockchain is a distributed registry technology that allows for secure recording of transactions in a registry at several locations at once and through several individuals without the need for central administration or intermediaries.

It must be understood that nowadays the maritime industry is still heavily dependent on paper records. One factor in this dependence is the poor standardization of electronic data exchange formats. [10]

One of the problems of cybersecurity in using IoT devices on ships can be centralized data storage and processing. To exclude a situation at which the malefactor enough to attack the unique device to put in danger all system it is possible to organize information storage by a principle blocked. Also using this mechanism, it is possible to realize reliably process of the coordination and signing of documents that will allow to leave partially from paper document circulation. [11]

It is also possible to implement with this mechanism:

-cargo tracking systems; 
-supply chain visibility systems;

-ship data registration system;

- global risk intelligence system;

-smart contract management system

-e-Insurance system;

Smart contracts are another fast-growing trend. These program contracts whose execution is based on blockchain technology. They are designed to automate the tracking of the execution of items set by the contract programmers. By using this technology, it is possible to implement a smart bill of lading template without much difficulty in sea shipping.

As soon as the application of smart contracts reaches a high level of development, the further plan of action will include the following: negotiation of freight rates directly between ship owners and their counterparties; automatic processing of payments, as well as the issuance of insurance policies and settlement of maritime insurance claims using Blockchain technology.

\section{Conclusions}

Take everything into account, the most actual trends in the development of IT technologies in maritime transport were highlighted: crew-free ships, IoT, systems with artificial intelligence, blockchain, smart contracts. It is worth noting that the schemes presented in this work are basic and can complement or include each other. By the more detail review the applications of these technologies, you can see that all of them are links in the same technological chain. It will be not too long to see a crewless vessel carrying cargo in smart containers that can command the successful completion of the contract by itself. Moreover, this transportation satisfies the "7R" rule.

\section{References}

1. S.S. Sokolov, N.B. Glebov, E.N. Antonova, A.P. Nyrkov, "The Safety Assessment of Critical Infrastructure Control System" IEEE International Conference "Quality Management, Transport and Information Security, Information Technologies", IT and QM and IS, 154-157 (2018) https://doi.org/10.1109/ITMQIS.2018.8524948

2. A.P. Nyrkov, N.B. Glebov, R.O. Novoselov, O.M. Alimov, S.G. Chernyi, "Databases Problems for Maritime Transport Industry on Platform Highload" IEEE International Conference "Quality Management, Transport and Information Security, Information Technologies", IT and QM and IS (2018) pp. 132-135.

3. A.P. Nyrkov, Y.F. Katorin, V.D. Gaskarov, Y.V. Kosyak, A.V. Sauchev, "Aggregation process for implementation of application security management based on risk assessment" IEEE NW Russia Young Researchers in Electrical and Electronic Engineering Conference (EIConRusNW), 98-101 (2018) https://doi.org/10.1109/EIConRus.2018.8317039

4. M. Kardakova, , I. Shipunov, A. Nyrkov, T. Knysh, "Cyber Security on Sea Transport" Advances in Intelligent Systems and Computing, 982, pp.481-490. (2020) https://doi.org/10.1007/978-3-030-19756-8_46

5. I.S. Shipunov, K.S. Voevodskiy, A.P. Nyrkov, Y.F. Katorin, Y.A. Gatchin, “About the Problems of Ensuring Information Security on Unmanned Ships" 2019 IEEE NW Russia Young Researchers in Electrical and Electronic Engineering Conference (EIConRusNW), 339-343.(2019) https://doi.org/10.1109/EIConRus.2019.8657219 
6. A.A. Zhilenkov, S.G. Chernyi, A.P. Nyrkov, S.S. Sokolov, "Optimization Problem of Thermal Field on Surface of Revolving Susceptor in Vapor-Phase Epitaxy Reactor", IOP Conf. Series: Earth and Environmental Science, 87(8), (2017) 082060. https://doi.org/10.1088/1755-1315/87/8/082060

7. A.P. Nyrkov, A.A. Zhilenkov, S.S. Sokolov "Hard- and Software Implementation of Emergency Prevention System for Maritime Transport" Autom Remote Control (2018) 79: 195. https://doi.org/10.1134/S0005117918010174

8. A.P. Nyrkov, A.A. Zhilenkov, S.S. Sokolov "Identification and tracking problems in qualimetry inspections in distributed control systems of drilling platforms." 2016 IEEE NW Russia Young Researchers in Electrical and Electronic Engineering Conference (EIConRusNW), 641-645 (2016) https://doi.org/10.1109/eiconrusnw.2016.7448265

9. A. Nekrasova, Z. Boriev, A. Nyrkov, S. Sokolov, "Modeling and optimization of transmission and processing of data in an information computer network", IOP Conf. Series: Materials Science and Engineering, 124 (1), (2016) 012080. https://doi.org/10.1088/1757-899X/124/1/012080

10. A.P. Nyrkov A. S. Belousov S. S. Sokolov "Algorithmic support of optimization of multicast data transmission in networks with dynamic routing", Modern Applied Science, 10, 5, 162-176, (2015) https://doi.org/10.5539/mas.v9n5p162

11. I.S. Shipunov, K.S. Voevodskiy, A.P. Nyrkov, Y.F. Katorin, "Trusted transport telemetry by using distributed databases" 2019 IEEE NW Russia Young Researchers in Electrical and Electronic Engineering Conference (EIConRusNW), 344-347 (2019) https://doi.org/10.1109/EIConRus. 2019.8657215 